Published online: 2020-01-15

Letter to the Editor

\title{
Regarding ethical issues in clinical research
}

\section{Dear Sir,}

This is regarding Dr. Urmila Thatte's meticulous work on "Ethical issues in clinical research". ${ }^{[1]}$ We would like to thank the author for providing detailed knowledge of ethical guidelines on clinical research. This article will be very useful for people involved in doing research on human beings.

All the national and international guidelines which are required for scientific publications in clinical research are clearly quoted.

\section{Venkata Ramana Vollala, Bhagath Kumar Potu}

Melaka Manipal Medical College (Manipal Campus), Manipal - 576104, Karnataka, India

\footnotetext{
Address for correspondence: Dr. Venkata Ramana Vollala, Melaka Manipal Medical College (Manipal Campus), Manipal - 576 104, Karnataka, India. E-mail: ramana_anat@yahoo.co.in
}

\section{REFERENCE}

1. Thatte $U$. Ethical issues in clinical research. Indian $\mathrm{J}$ Plast Surg 2007;40:2-2. 